\title{
A Study on the Impact of Coffee Service Quality on Customer Loyalty
}

\author{
Sunmin Lee ${ }^{1}$, Jungsoo Lee ${ }^{2}$, Jinsup Kim ${ }^{3}$, Sunyoung Park ${ }^{4}$, and Hakyun Kim ${ }^{5 *}$ \\ 1,2,3,4 Doctoral Student, Graduate School of Information Systems, Pukyong National \\ Univ., Busan, Korea \\ ${ }^{5}$ Professor, Division of Business, Pukyong National Univ., Busan, Korea \\ ${ }^{1}$ sunminss@naver.com, ${ }^{2}$ scorpion@bufs.ac.kr, ${ }^{3}$ junhici@naver.com, \\ 4sun1234us@hanmail.net,.5*kimhk@pknu.ac.kr
}

\begin{abstract}
In a coffee shop, the physical environment, the taste of the drink, the marketing, and the diversification of the menu provide choices for customers to visit and revisit decisions. Coffee consumers are buying based on factors that play an important role in their purchasing decisions among the unique characteristics of coffee. The selective characteristics of the younger generation with high coffee shop usage rates are likely to be different from those of the middle-aged and elderly. Coffee is a representative food service industry that satisfies human basic needs. Coffee consumers make purchase decisions based on the unique characteristics of each coffee shop. The selection characteristics of coffee shops, which are applied to the younger generation, whose use of coffee shops is relatively high, will be different from those of the middle and elderly generations. In addition to coffee, coffee consumers choose coffee shops for a variety of purposes, such as simple meals, study, work, and a comfortable rest area. To summarize the results of the empirical analysis of this study, first, it was confirmed that female college students in Busan are not affected by the physical environment in forming positive emotions and loyalty in relation to the service quality of coffee. Second, the previous study shows the same results as this study because it was not affected by physical and environmental factors in service quality. Third, in the case of a franchise coffee shop, customers must be able to participate emotionally, so a strategy to develop various service quality factors and continuously improve quality is needed. Fourth, since most of the customers who use coffee shops are in their twenties and many women go to college, managers should pay attention to the products and services they prefer.
\end{abstract}

Keywords: Interaction, Physical environment, Result quality, Representativeness, Diversity

\section{Introduction}

The domestic coffee market was dominated by instant coffee developed as a military food for the U.S. military during the Korean War until the mid-1990s, but changed greatly in 1996 due to Starbucks' entry into the country and the spread of espresso coffee. The domestic coffee market has been expanding rapidly recently, with new products that maintain the luxurious taste and quality of coffee beans pouring in and brand coffee shops aggressively marketing them[1]. Starbucks Reserve Bar, Blue Bottle, Coffee Artworks, Angelinos Specialty, and

Article history:

Received (October 18, 2020), Review Result (November 21, 2020), Accepted (January 9, 2021) 
Ediya Coffee Lab are representative brands. With regard to the opening of high-end stores, Starbucks has opened 50 in Korea, the second largest number after China. This is the highest among major countries, with 9.8 per 10 million people [2]. Most of the preceding studies have examined the connection between price sensitivity and service quality, customer satisfaction, service quality and behavior, but not many have empirically analyzed the relationship between the service quality of coffee and positive emotions and loyalty.

\section{Theoretical background}

\subsection{Service quality}

The service quality measurement tool is the SERVQUAL model. PZB initially divided the subfactors into 10 categories for measuring service quality: tangibility, responsiveness, reliability, ability, etiquette, creditworthiness, stability, accessibility, communication, and understanding of customers [3]. The overlapping factors were then grouped together into five types of Service Quality (SERVQUAL) metrics: tangibility, reliability, responsiveness, certainty, and empathy. The result of regression analysis, the coefficient of determination, was higher in the SERVPERF model. Thus, the SERVPERF model, which measures the perception of service performance, actually proved suitable for measuring service quality. This logic is considered to reflect consumer perception and market phenomena better than the SERVQUAL model centered on process quality and the two-dimensional service quality measurement model of course quality and outcome quality. The tool was then called the Coffee SERV model [4].

\subsubsection{Interaction}

For coffee shops, fairness management is very important so that consumers do not perceive unfairness because they react more sensitively to those who perceive a service as unfair than to those who perceive it as fair [5]. For customers, it can be said that the provision of a comfortable atmosphere and place for customers to use is a more important service than the physical facilities of the coffee shop or service determined by regulations.

\subsubsection{Physical environment}

Physical environment refers to convenient access, convenient parking, a clean and pleasant environment, indoor atmosphere, and bathroom comfort. In other words, The physical environment of the service is the meticulous care and consideration of the supplier providing the service to the customer, such as physical facilities, equipment and communication machinery [6].

\subsubsection{Result quality}

Result quality means the appropriate temperature of the coffee, the freshness of the coffee, the optimal taste, the maintenance of consistent taste, the maintenance of always balanced taste, etc. Through multi-recursive analysis, the connection between quality of service and customer satisfaction was verified, but the interaction quality and result quality did not have a significant impact on each other, while the physical environment had a significant impact [7].

As a result of analyzing the effect of the service quality of domestic coffee shops on a positive emotional response, it has a greater influence on the positive emotional response of 
customers than the quality, responsiveness and cleanliness of the coffee shop and the side menu provided with coffee.

\subsubsection{Representativeness}

The optional attributes of a coffee shop such as the physical environment, human services, study and work environment, ease of access and brand awareness all significantly affect customer satisfaction [8]. It is expected to provide useful information for establishing efficient marketing strategies for domestic and international brand coffee shops to strengthen competitiveness in terms of store and sales volume [9]. Since customers who use private coffee shops have lower expectations for them than for franchise coffee shops, it is possible to analyze that service quality efficiency is relatively superior.

\subsubsection{Diversity}

Diversity refers to various flavors of coffee, beverages other than coffee, and various menus. The preceding research on the selective attributes of coffee specialty stores was conducted by deriving service quality, coffee quality, facilities, accessibility, coffee promotion, menu diversity, and brand factors [10].

\subsection{Positive emotions}

Positive emotions are an area where the quality of service that customers feel is very important, and unlike consumer behavior in the past, where rational decision making was dominant, recent studies have shown that the temporary sensibility experienced by consumers affects consumer behavior or attitude, while the service can measure a consumer's subjective feelings. Positive emotional responses are referred to on a scale [10].

\subsection{Loyalty}

Loyalty refers to the willingness to visit again, the degree of priority consideration when choosing a coffee shop, and the willingness to visit continuously. In other words, it is defined as the level of repetitive purchasing behavior with a favorable feeling for a specific brand or store. Many previous studies on quality of service and loyalty have identified significant causal relationships.

\section{Research design}

\subsection{Research model}

This study focused on analyzing the relationship of the impact of coffee quality on positive emotions and loyalty. Based on the Hierarchical Service Quality Model (HSQM) and the Coffee SERV model [4], interaction, physical environment, outcome quality and representativeness, and diversity were expected to have a significant impact on positive feelings and loyalty, and the service quality decision factors were selected. The proposed research model is shown in [Figure 1]. 


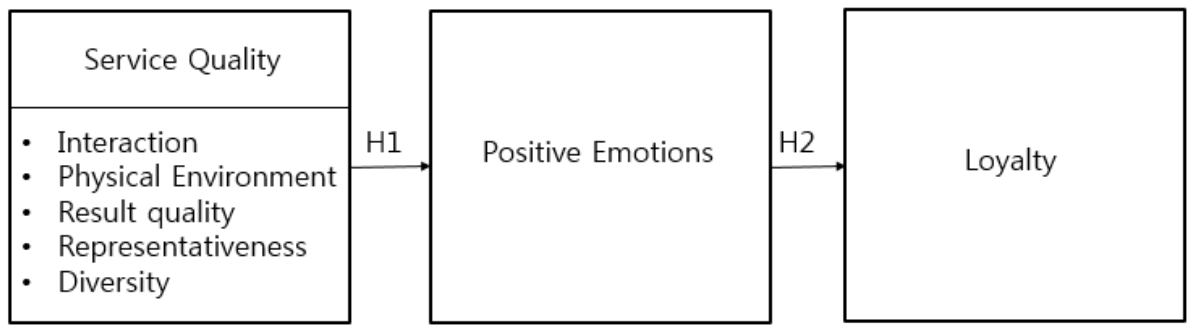

Figure 1. Research model

\subsection{Research hypotheses}

\subsubsection{Hypotheses on service quality and positive emotions}

In this study, the following hypotheses were established based on prior studies.

Hypothesis H1-1: Interaction have a significant effect on positive emotions.

Hypothesis H1-2: The physical environment have a significant impact on positive emotions.

Hypothesis H1-3: Result quality have a significant effect on positive emotions.

Hypothesis H1-4: Representativeness have a significant effect on positive emotions.

Hypothesis H1-5: Diversity have a significant effect on positive emotions.

\subsubsection{Hypothesis about positive emotions and loyalty}

In this study, the following hypothesis was established based on prior studies.

Hypothesis H2: Positive feelings have a significant impact on loyalty.

\subsection{Empirical analysis and results}

\subsubsection{Data collection and sample characteristics}

A total of 120 people were surveyed. The basic statistics of the survey are as follows. All of the respondents were university students, and they are enrolled in a department specializing in service. The gender distribution is $100 \%$ women, and the age distribution is $91.6 \%$ for those in their $20 \mathrm{~s}$, and $8.4 \%$ for those in their $40 \mathrm{~s}$ and $50 \mathrm{~s}$. In terms of annual income, less than 20 million won accounted for $90 \%$, and $100 \%$ of respondents were experienced in positive emotions and loyalty of coffee service quality.

\subsubsection{Data analysis method}

The statistical analysis of the questionnaire used the statistical package SPSS 22.0 for basic statistics. Smart PLS 2.0, a structural equation package, was used for factor analysis, validation and hypothesis testing. Concentration effectiveness is judged by factor loading values, Composition Reliability (C.R.) and Average Variance Extraction (AVE). Typical reference values are 0.6 or more for factor load value, 0.7 or more for C. R. value, and 0.5 or more for AVE value. Since the square root value of AVE is larger than the correlation coefficient, the discriminant validity is reasonable. As a result of exploratory factor analysis, six of the 30 question items are measured. Items were removed because the factor loading amount was not significant, and it was analyzed with a total of 24 questions items. 
Table 1. Reliability and internal consistency

\begin{tabular}{|c|c|c|c|c|}
\hline Variable & Factor loading & AVE & C. R. & Cronbach's $\alpha$ \\
\hline \multirow{3}{*}{ Interaction } & 0.783 & \multirow{3}{*}{0.638} & \multirow{3}{*}{0.841} & \multirow{3}{*}{0.717} \\
\hline & 0.782 & & & \\
\hline & 0.829 & & & \\
\hline \multirow{3}{*}{ Physical Environment } & 0.784 & \multirow{3}{*}{0.603} & \multirow{3}{*}{0.819} & \multirow{3}{*}{0.675} \\
\hline & 0.828 & & & \\
\hline & 0.713 & & & \\
\hline \multirow{5}{*}{ Result quality } & 0.725 & \multirow{5}{*}{0.623} & \multirow{5}{*}{0.891} & \multirow{5}{*}{0.848} \\
\hline & 0.782 & & & \\
\hline & 0.832 & & & \\
\hline & 0.830 & & & \\
\hline & 0.771 & & & \\
\hline \multirow{2}{*}{ Representativeness } & 0.862 & \multirow{2}{*}{0.787} & \multirow{2}{*}{0.881} & \multirow{2}{*}{0.733} \\
\hline & 0.911 & & & \\
\hline \multirow{3}{*}{ Diversity } & 0.785 & \multirow{3}{*}{0.612} & \multirow{3}{*}{0.825} & \multirow{3}{*}{0.687} \\
\hline & 0.784 & & & \\
\hline & 0.778 & & & \\
\hline \multirow{4}{*}{ Positive Emotions } & 0.680 & \multirow{4}{*}{0.679} & \multirow{4}{*}{0.785} & \multirow{4}{*}{0.635} \\
\hline & 0.626 & & & \\
\hline & 0.690 & & & \\
\hline & 0.764 & & & \\
\hline \multirow{4}{*}{ Loyalty } & 0.849 & \multirow{4}{*}{0.732} & \multirow{4}{*}{0.916} & \multirow{4}{*}{0.878} \\
\hline & 0.842 & & & \\
\hline & 0.856 & & & \\
\hline & 0.875 & & & \\
\hline
\end{tabular}

Table 2. Correlation and discriminant validity

\begin{tabular}{|c|c|c|c|c|c|c|c|c|}
\hline Variable & AVE & 1 & 2 & 3 & 4 & 5 & 6 & 7 \\
\hline Interaction & 0.638 & 0.725 & & & & & & \\
\hline Physical Environment & 0.603 & 0.556 & 0.736 & & & & & \\
\hline Result quality & 0.623 & 0.725 & 0.723 & 0.789 & & & & \\
\hline Representativeness & 0.787 & 0.583 & 0.621 & 0.652 & 0.887 & & & \\
\hline Diversity & 0.612 & 0.484 & 0.688 & 0.591 & 0.597 & 0.782 & & \\
\hline Positive Emotions & 0.679 & 0.707 & 0.681 & 0.771 & 0.688 & 0.669 & 0.824 & \\
\hline Loyalty & 0.732 & 0.641 & 0.614 & 0.699 & 0.575 & 0.497 & 0.688 & 0.855 \\
\hline
\end{tabular}




\subsubsection{Verification of structural model}

Smart PLS 2.0 was used as the structural equation model for hypothesis testing, and the path coefficient and coefficient of determination $\left(\mathrm{R}^{2}\right)$ between variables were derived from the research model. If the $\mathrm{R}^{2}$ value is 0.26 or more, the degree of fitness can be expressed as "high," and if it is 0.26 to 0.13 , it can be expressed as "middle," and if it is less than 0.13 , it can be expressed as "low" [9]. The coefficient of determination $\left(\mathrm{R}^{2}\right)$ for intent to use $(0.814)$ and the act of abuse (0.149) was shown as high and medium, respectively.

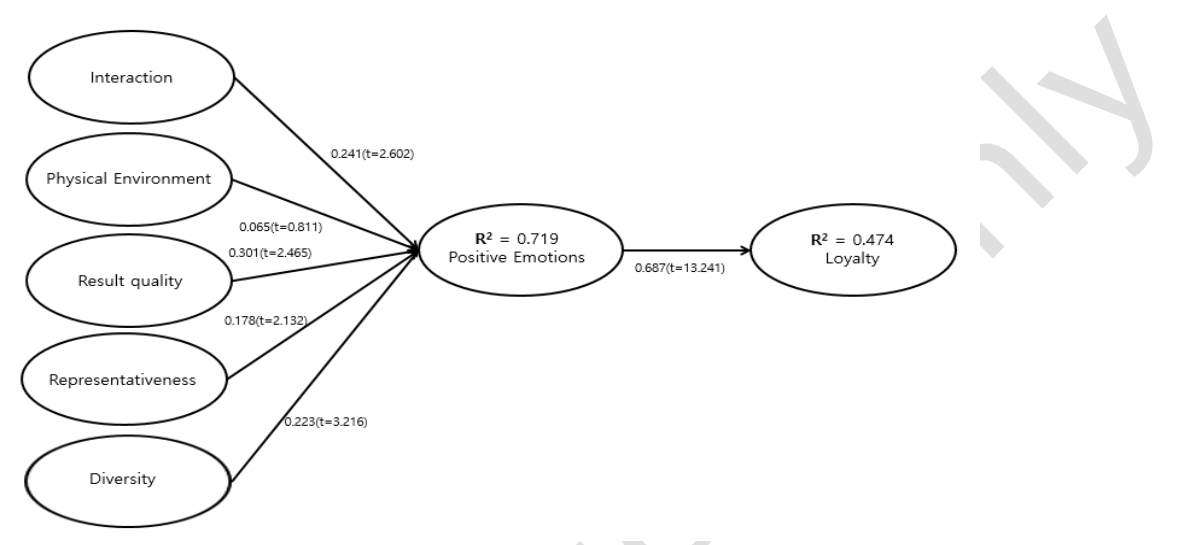

Figure 2. Results of the research model

The proposed hypothesis H1 was sub-selected, and H2 was adopted. First, hypothesis H1-1 that "interaction will have a significant effect on positive emotions" was adopted. Interaction has been shown to have significant effects on positive emotions $(\beta=0.241, t=2.602$. and $\mathrm{p}<0.05)$. This means that interactions in coffee service quality have a significant effect on positive feelings. Second, hypothesis H1-2 that "the physical environment will have a significant effect on positive emotions" was rejected. The physical environment was shown to have no significant effect on positive emotions $(\beta=0.065, \mathrm{t}=0.811, \mathrm{p}<0.05)$. This means that in coffee service quality, the physical environment has no significant effect on positive feelings. This supports the same results in a preceding study [9]. Third, hypothesis H1-3 that "result quality will have a significant effect on positive emotions" was adopted. Result quality has been shown to have a significant effect on positive feelings $(\beta=0.301, t=2.465, p<0.05)$. This means that in coffee service quality, result quality has a significant effect on positive emotions. Fourth, hypothesis H1-4 that "representativeness will have a significant effect on positive emotions" was adopted. Representativeness was shown to have a significant effect on positive feelings $(\beta=0.178, \mathrm{t}=2.132, \mathrm{p}<0.05)$. This means that representativeness in coffee service quality has a significant impact on positive feelings. Fifth, hypothesis H1-5 that "diversity will have a significant effect on positive emotions" was adopted. Diversity has been shown to have significant effects on positive emotions $(\beta=0.223, t=3.216$ and $p<0.05)$. This means that diversity in coffee service quality has a significant impact on positive feelings. Sixth, hypothesis H2 that "positive feelings will have a significant impact on loyalty" was adopted. Positive emotions were shown to have a significant effect on loyalty $(\beta=0.687$, $\mathrm{t}=13.241$, and $\mathrm{p} 0.00 .05)$. This means that positive feelings in coffee service quality have a significant impact on loyalty. 


\section{Conclusions}

In this study, female university students in Busan were selected as the determinants of service quality of coffee by interaction, physical environment, result quality, representativeness, and diversity, and the impact of service quality on loyalty was demonstrated through the medium of positive emotions. To summarize the results of the empirical analysis in this study, firstly, H1-1, the hypothesis that interactions affect positive emotions, was adopted. Second, hypothesis H1-2 that the physical environment affects positive emotions was rejected. Third, hypothesis H1-3 that the resulting quality affects positive emotions was adopted. Fourth, hypothesis H1-4 that representativeness affects positive feelings was adopted. Fifth, hypothesis H1-5 that diversity affects positive emotions was adopted. Sixth, hypothesis $\mathrm{H} 2$ that positive emotions affect loyalty was adopted.

Based on the empirical analysis results, the following implications were derived. First, it was confirmed that female college students in Busan are not affected by the physical environment in forming positive emotions and loyalty in relation to the service quality of coffee. Second, the previous study shows the same results as this study because it was not affected by physical and environmental factors in service quality. Third, in the case of a franchise coffee shop, customers must be able to participate emotionally, so a strategy to develop various service quality factors and continuously improve quality is needed. Fourth, since most of the customers who use coffee shops are in their twenties and many women go to college, managers should pay attention to the products and services they prefer.

\section{Acknowledgements}

This research was supported by the Pukyoung National University Development Project Research Fund, 2020.

\section{References}

[1] W. Jung, S. Kim, and I. Jung, "The Regulations of Non-face-to-face Channels and Applications," Korea Insurance Research Institute, (2019)

[2] S. Jung, K. Park, "Relationship between the service quality of non-face-to-face channels and the insurance purchase intention in the life insurance industry," Financial Planning Review, vol.10, no.3, pp.65-86, (2017)

[3] A. Parasuraman, V. A. Zeithaml, L. L. Berry, and SERVQUAL, "a multiple-item scale for measuring consumer perceptions of service quality," Journal of Retailing, vol.64, no.1, pp.12-40, (1988)

[4] https://www.fss.or.kr/fss/kr/promo/bodobbs_view.jsp?seqno $=23062 \&$ no $=15338 \&$ s_title $=\&$ s_kind $=\& p a g e=1$, Apr., (2020)

[5] http://www.law.go.kr, Aug., (2020)

[6] S. Fournier, D. G. Mick, "Rediscovering satisfaction. journal marketing," vol.63, no.0, pp.5-15, (1999)

[7] E. W. Anderson and C. Fornel, "A Customer satisfaction research prospectus, service quality: new direction in theory and practice," Roland T. Rust and Richard L. Oliver (eds.), Thousand Oaks, CA: Sage Publications, (1994)

[8] S. Jung, "A study on relationship between the service quality of non-face-to-face channels and the insurance purchase intention: focused on the life insurance industry," Thesis for a Doctorate, Graduate School of Dong Eui University, (2018)

[9] J. Cohen, "Statistical power analysis for the behavioral science (2nd)," Hillsdale, New Jersey: Lawrence Erlbaum Associates, pp.90-100, (1988)

[10] Y. Park, "The Effect of service quality of coffee shop on customer revisit and recommendation intention focusing on Gyeonggi area,” Journal of Hotel \& Resort, vol.18, no.1, pp.277-292, (2019) 
This page is empty by intention. 